\title{
Noturnos urbanos. Interpelações da literatura para uma ética da pesquisa
}

\section{Urban nights. The inquiries from literature for research ethics}

\author{
Luis Antonio dos Santos Baptista* \\ Professor da Universidade Federal Fluminense - UFF, Niterói, RJ, Brasil
}

\begin{abstract}
RESUMO
Este artigo objetiva problematizar a concepção de ética da pesquisa nas ciências humanas baseada no respeito e no acolhimento ao outro. Utiliza como ponto de partida conceitual, entre outros referenciais teóricos, o conceito de poder como produção, de Michel Foucault e desenvolvido no ensaio "A Vida dos Homens Infames". No uso deste conceito, argumentamos sobre os efeitos do poder na construção e análise dos objetos das práticas psi. Um outro objetivo seria ressaltar a relevância do enfoque transdisciplinar para a reflexão sobre as políticas da ética nas ciências humanas. No diálogo com a literatura e com a fotografia, pretendemos criar indagações que tensionem as atitudes naturalizadas presentes no humanismo das ciências humanas.
\end{abstract}

Palavras-chave: Literatura, Cidade, Ética.

\section{ABSTRACT}

The objective of this article is to discuss the conception of research ethics in the humanities based on the respect and shelter towards the other. It utilizes as a conceptual starting point, among other theoretical references, the concept of power as production by Michel Foucault and developed in the essay, "The Life of Infamous Men." In the use of this concept, the work considers the effects of power in the construction and analysis of the objects of psychological practices. Another objective is to highlight the relevance of a transdisciplinary approach to reflect upon the politics of ethics in the humanities. Dialoguing with literature and photography, the intent is to arouse questions that give tension to the naturalized attitudes present in the humanism of the humanities.

Keywords: Literature, City, Ethics.

Algo inominável ganha carne quando irradiado pela luz da razão. Um ato impessoal, um gesto ao acaso transformam-se, tocados por esta luz, em forma legível e subordinam-se aos desígnios da precisão. O que antes era informe, ambíguo, agora reluz nas páginas dos escritos sobre o humano com a clareza pertinente aos limites de um corpo. A carne produzida por esta luminosidade ganha vida, não por meio daquilo que a 
faz pulsar, mas por meio de uma nomeação clara, delimitada por fronteiras definitivas. Na noite, onde eles habitavam, nada era um, nenhuma diferença se eternizava, nenhuma forma vivia em paz; existiria apenas uma força que nunca ousava dizer seu nome ou sua origem. Delitos, sofrimentos, comportamentos desviantes, sexualidades ilustrariam a cintilância da verdade encarnada nos, agora, indivíduos ou sujeitos. Do efeito deste fulgor, um eu concentra, confessa, exibe a potência do seu contorno. Nos escritos sobre a alma humana, a razão médica, psicológica ou jurídica faz falar o que antes era um possível silêncio, um provável ainda não, um por vir, um nada, ou o que a luz da razão não suporta quando confrontada pelo seu próprio brilho. São textos de seqüestro. Nas páginas sobre a psique, ou sobre os fora da lei ou da norma, histórias são contadas, dissipando a impertinência ou o incômodo do inominável. Seria inocente este aniquilamento?

Dar voz ao outro, escutar com cuidado o que tem a dizer, manter incógnito o que poderá ofendê-lo ou desqualificá-lo, são procedimentos clássicos de uma ética da pesquisa nas ciências humanas. Prescrições são exigidas ao pesquisador para que o texto, sobre o seu objeto de análise, respeite a verdade daquele que a sua pesquisa objetiva compreender. Preceitos éticos são acionados para libertar a voz não ouvida e impelí-la a identificar-se. Antes da investigação, o excluído, a existência opaca, o infame habitariam, para esta proposta ética, o impuro mundo do anonimato. Lá, a noite, ou a escuridão, seria apenas adjetivo, morada do amorfo, do mal ou do sofrimento, território preocupante para o humanismo libertário que enseja a oportunidade para que a palavra veraz seja dita. O processo investigativo os retiraria deste universo, legando aos mesmos a claridade de um corpo delimitado por uma geografia incontestável. A ética do respeito emancipa-os e os faz falar ruidosamente. Um respeito vaidoso e desatento às engrenagens produtoras da luminosidade que pretensamente faz conhecer o seu objeto. Neste procedimento acolhedor de uma diferença libertada das trevas, a alma do pesquisador avoluma-se, engrandece-se, mas o olhar se mantém intacto como se o objeto da sua visada não perscrutasse ou atravessasse a sua carne. O corpo, após a pesquisa, continuaria ileso junto à alma robusta. Noite e luz permaneceriam incompatíveis, à semelhança da lógica binária do bem e do mal. Sombras e restos de escuridão, ignorados por esta escuta acolhedora, persistiriam até a próxima captura.

Este ensaio deseja deter-se na atenção à voz ainda não dita, à matéria informe, ao gesto sem mensagens a enviar que habitam a escuridão do anonimato, à morada na qual a diferença, afirmando a sua intensidade, escapa do encarceramento identitário ${ }^{1}$. Pretende aproximar-se da 
literatura e da fotografia para problematizar políticas de metodologias de pesquisa cuja luz desvela, liberta, mas aniquila o que resiste a uma concisa conclusão. Deseja deter-se no prenúncio de uma ética inspirada no inacabamento de existências noturnas, vidas infames capturadas pelos escritos da ética do respeito. Narrativas finalizadas, inspiradas no otimismo alegre da emancipação da ciência ou da arte, como no amargo pessimismo gerado por uma utopia destruída, inspiram a escrita deste ensaio, que se opõe radicalmente a esta alegria e a este ressentimento. Ambos são violentos pela desatenção ao que extrapola o limite das suas idéias, como se nada acontecesse exigindo uma certa urgência. Vidas solapadas, do ontem e do agora, não apelariam à salvação ou à glória de serem vítimas exclusivas de agruras. Libertação e exclusividade que impedem essas existências de ultrapassarem suas bordas e nada dizem sobre a impessoalidade da dor. Acerca das vidas infames, alerta-nos Foucault (1992, p.97):

\begin{abstract}
Para que algo delas chegasse até nós, foi porém necessário que um feixe de luz, ao menos por um instante, as viesse iluminar. Luz essa que Ihes vem do exterior. Aquilo que as arranca à noite em que elas poderiam, e talvez devessem sempre, ter ficado, é o encontro com o poder; sem este choque, é indubitável que nenhuma palavra teria ficado para lembrar o seu fugidio trajeto.
\end{abstract}

$\mathrm{Na}$ noite, lugar onde elas deveriam ter ficado, esboços de imagens, prenúncios de experimentações do existir são incansavelmente criados por lutas invisíveis, porque a vida não as dá sossego. Estas lutas podem ser vistas no corpo que pulsa sem dono, nos rastros de uma ausência, no gesto suspenso por êxtase ou dor, na frase cortada pelo espanto, ou na narrativa interrompida por falta de ar. São enfrentamentos noturnos nos quais nada se acomoda em geografias imóveis ou no tempo pacífico dos calendários. Neste espaço, onde a forma de algo vivo se faz no desassossego, a violência do encerramento de qualquer história é inexistente. Ali, entre sombras e escuridão, a felicidade e a barbárie desconhecem um único formato ou a palavra derradeira. Imagem e forma ignoram a perenidade da essência, assim como a função de representar ou evocar alguma coisa. Neste território noturno, a estética é inseparável de uma ética. Nada está terminado e ninguém, humano ou inumano, ousa dizer, para todo o sempre, sou ou não sou. O que vislumbramos nos escritos onde a noite é sabotada por uma poderosa iluminação? 


\begin{abstract}
A luz
O comportamento identificado na pequena Regina, quando ela estava com 18 meses, e que demandou o presente procedimento, consistia em manipular-se nas partes pudendas, introduzindo objetos em sua vagina, como canetas, além de apresentar-se de forma agressiva consigo mesma e com os demais familiares (puxando seu cabelo, jogando a si mesma da escada, quebrando brinquedos, etc). A menina também exibia comportamento manipulatório com Rosângela (sua irmã mais nova), sendo detectadas situações em que lambia a vagina da irmã de meses.
\end{abstract}

Demarcou-se, no decorrer das intervenções, que apesar da Sra. Sueli (sua mãe) não conseguir estabelecer diálogo com o cunhado, permitia que Regina permanecesse no quarto daquele sozinha, após o retorno da jornada laborativa do cunhado Sr. Orlando.

Tanto a Sra. Sueli, quanto seu companheiro afirmam que a menina ficava por horas no quarto do tio com a porta fechada. Relatou a Sra. Sueli que, numa dessas ocasiões, ouvira um grande estrondo vindo do interior do cômodo e, como não teria nenhum diálogo com o cunhado, foi buscar o marido que se encontrava fora de casa para que ele questionasse o que teria ocorrido e retirasse a filha daquele quarto.

Embora apresente dificuldades em se defrontar com os comportamentos que Regina apresentava, o Sr. Almir (seu pai) afirmou que assistiu à primogênita lamber a vagina da pequena Rosângela, numa situação a que foi chamado, pela Sra. Sueli, para constatar o que ela já Ihe havia relatado.

Relatos de familiares maternos confirmam o comportamento agitado e irritadiço de Regina. Sua tia Vera teria visto a menina tocar na genitália de seu marido, algo que, embora tenha estranhado, não the provocou maiores questionamentos.

Em nosso primeiro contato com Regina, observamos uma menina muito agitada, demonstrando um alheamento frenético frente às consignas, irritadiça e sem controle dos esfíncteres. Após a saída da família da residência do Sr. Orlando, Regina apresentou mudanças de comportamento significativamente positivas, estando mais calma, centrada e, segundo a mãe, tendo cessado a agressividade.

O Sr. Orlando conta 32 anos e labora como padeiro no estabelecimento Sabores da Roça, localizado no Mareara-MA. Afirmou que permanece a maior parte do dia no trabalho e, à noite, frequenta diariamente a Igreja Evangélica. Avaliamos que seu relato da extensa carga horária buscou comprovar que tinha pouco contato com sua cunhada e sobrinhas. 
Segundo ele, ausenta-se para trabalhar às 5 horas e retorna à casa às 23 horas.

O Sr. Orlando negou que ficasse com Regina em seu quarto a portas fechadas, manifestando irritação perante tal questionamento. Mas, confirmou que costumava ter biscoitos em seu quarto que eram ofertados à sobrinha. Avaliamos que a dinâmica familiar em análise possui desdobramentos perante o comportamento sexualizado que foi apresentado por Regina, e que a tomada de atitudes protetivas pela genitora se revelou positiva na superação do quadro. Todavia, a sintomatologia mais grave e preocupante consistia em evidentes e inapeláveis sintomas de que Regina vinha sendo submetida à violência sexual.

Embora possamos demarcar conclusivamente que a menina foi submetida a atos sexualmente abusivos, o testemunho linear da menina não poderia ser utilizado como estratégia na identificação do abusador, sendo construído quadro complexo, em que analisamos todas as narrativas colhidas e as próprias intervenções com a menina Regina. Diante do exposto, podemos considerar que não identificamos indícios que nos levem a considerar que o Sr. Almir tenha cometido violência sexual contra a filha.

Todavia, o comportamento expresso pelo Sr. Orlando e as narrativas sobre seu comportamento pregresso nos levam a considerar que sua conduta denuncia extremada fragilidade no trato com adultos e com o mundo, sendo também detectável imaturidade emocional significativa que podem estar articuladas com perfil compatível com o de pedofilia ${ }^{2}$.

\section{A cidade da luz}

Após a incidência da luz científica nesta família, retirando a mesma do anonimato da escuridão através do laudo, podemos formular as seguintes perguntas: Regina foi ou não foi violentada? O Sr. Orlando seria o verdadeiro culpado? E o pai? Regina estaria mentindo? Quem é o culpado? Quem é Regina? Este episódio seria uma ficção ou uma descrição verídica de um fato comprovadamente científico? Qual a diferença?

Além do laudo recente de Regina, uma outra mulher é colocada sob suspeita em prontuário escrito no início do século XX. Ela se chama Antônia. Quando iluminada pelo clarão que vem de fora, incidindo na sua matéria informe, essa ganha nitidez na seguinte forma:

[...] Freqüentou o colégio onde aprendeu a ler e escrever. Não consta que houvesse padecido de moléstias graves. Foi sempre um pouco débil de constituição, como de regra sucede com os mestiços entre nós. Por morte de seu progenitor é que começa a 


\begin{abstract}
sua história mental propriamente dita. Usufruindo um pequeno rendimento de herança, entregue a si mesma, começou a revelar-se incapaz de gerir seus bens, que dissipava sem conta [...]. Um pouco mais tarde, sua conduta entrou a manifestar singularidades. Certa vez, comprou trajes masculinos e saiu a viajar neste estado. Foi reconhecida como mulher e presa pela polícia [...]. Achamos, pelo exposto, que se trata de uma degenerada fraca de espírito em que se vai instalando pouco a pouco a demência. (CUNHA, 1986, p. 143)
\end{abstract}

Regina e Antônia, frutos do clarão luminoso, ocupam a cidade da luz através das determinações da sexualidade e da raça. Sexo e raça as formatam e as fazem falar. Após a captura, apresentam a nitidez inconfundível dos seus contornos. Nesta urbe, os monumentos, o traçado retilíneo das ruas, o desenho das casas permitem a qualquer um sentir-se protegido no seu caminhar. Na cidade da luz, o perder-se inexiste; a racionalidade inscrita nas pedras seria o guia; passa-se e encontra-se o que se deseja. Através dela, a utopia se realiza. O estranhamento frente às imagens urbanas, ao corpo, ao espírito do andante nunca se sucederá. Esta urbe possui identidade, seus planejadores a deram alma e, desta forma, na próxima visita, ninguém encontrará surpresas. A clareza do mapa e a lembrança atenta aos símbolos que representam a sua essência, impedirão, a quem retorne no futuro, o incômodo do inesperado.

Em algumas cidades, o mapa é ineficiente. Certos viajantes são atraídos pelos detritos, por coisa tortas, por sombras que interrompem e incitam o recomeçar interminável do percurso. Conhecemos estas cidades nos perdendo ${ }^{3}$; uma perda que inventará atalhos, encruzilhadas, vias nunca usadas, porém sem nenhum júbilo orgulhoso do inventor. Inventa-se porque o que ele encontra neste perder-se poderá ser insuportável se o viajante lastimar ou tentar recuperar a eficiência dos velhos parâmetros. Cria-se porque os espaços não são desenhados na mais completa paz. Dejetos jogados fora, esquecidos por outros viajantes ansiosos em finalizar a caminhada, chamar-lhe-ão a atenção, exigindo-lhe a mudança do rumo. Ele se dará conta de que aquilo, que o guiou em viagens anteriores e sempre o conduziu com conforto pelos caminhos, poderá não servir para nada. Descobre que o mapa, a bússola ou a luz condutora do olhar dos descobridores, levarão ao lugar reconhecível, aos imprevistos já vistos, ensejando as mesmas soluções, impedindo o enfrentamento de agruras ou acontecimentos inesperados. Percebe, apesar da fadiga por interromper e recomeçar o seu trajeto, que a cidade alvo que o sufocava por não a encontrar, a verdade almejada, a resposta definitiva seriam um objeto perecível como os alimentos do seu 
farnel. Nesta metodologia suja, torta, onde em cada desvio algo fenece, na qual o objeto não estará a sua espera, ele não chegará ileso, nada estará encerrado.

Em uma capital chamada São Paulo, uma folha amarelada pelo tempo induziu alguém a parar e a recomeçar, por outra via, o caminho. No papel envelhecido, o texto noturno enfrentava incansavelmente o poder da luz. Cunha (1986), atenta aos detritos urbanos, apresenta-nos Florinda, 58 anos, negra, semi-analfabeta, que possuía uma fotografia para a sua identificação. No lugar, onde viveu muitos anos, a foto era necessária para o conhecimento de alguns dos seus habitantes. Esta mulher escrevia cartas que nunca saíam do mesmo lugar ${ }^{4}$. Certa vez, Florinda redigiu no papel, agora amarelado, o seguinte texto para o seu filho:

[...] A iducação do lar não te fartou e a estrução que chegou escureceste a luz mais clara, eu aqui como indigente para mais depressa a vida findar [...]. Inbarquei no da carro da Segurança publica acompanhada de dois sordados paizanos [...]. Tu pagou o leite que mamou as dores que sofri e noites malpasadas. A Qui no degredo incarserada viajei em vagão de criminoso [...] Deos mi deu olhos e não mi deu lágrimas as lágrimas as lágrimas são tuas. Qui si acabe essa mardita e mal fadada apirsiguição Qui este poco resto de vida mal tratada quero morer fora da prizão quero sortar aultima respiração num canto sucegada...Guarde esta para algum dia lembrar-se de mim (CUNHA, 1986, p. 117118).

Esta carta foi escrita em 1916, no Hospício do Juquery, São Paulo, e nunca chegou ao seu destino. Encontra-se, até hoje, anexada ao prontuário gasto pelo tempo. Os textos escritos por pacientes psiquiátricos serviam como pistas, traços para o entendimento da enfermidade. A doença mental, segundo a razão científica da época, bloqueava a comunicação com o mundo exterior, impedia o entendimento do que fosse o outro, e, desta forma, a alma deteriorada não poderia expressar-se. No texto escrito por Florinda, iluminado pela luz da ciência, inexistia qualquer sentido que transgredisse o destino da mulher louca, negra e miserável. As palavras exasperadas, na recusa do cárcere que as fixava na forma nítida da morbidez, transformavam-se em indícios valiosos para o alcance da veracidade da loucura pistas que indicavam que nenhum afeto ou revolta deveriam ultrapassar os muros do hospício. O impedimento da saída da missiva para o filho não se resumia a um ato repressivo: nas cidades iluminadas pela ordem médica, cada coisa deveria permanecer no seu devido lugar. A proibição da carta de sair do manicômio executava a utopia da higiene urbana, no 
intuito de proteger o citadino dos perigos das misturas; à semelhança dos vegetais, deveríamos estar atentos ao solo fértil e à luz necessária para não adoecermos ou violarmos a ordem do espírito e da cidade. No lugar apropriado, sementes do futuro, contidas nas essências da alma e do corpo, desenvolver-se-íam, indo ao encontro das suas verdades. $\mathrm{Na}$ cidade higienizada, a iluminação e o solo propício estariam prevenidos da errância do inominável. Contágios iminentes poderiam desenraizar promessas de uma asséptica felicidade. Por que a foto de Florinda era necessária para o conhecimento da sua enfermidade? O que aconteceu a Regina? Quem é o culpado?

A historiadora Maria Clementina Cunha, quando nos traz a história do J uquery por meio desta figura infame, não deseja dar voz ao humilhado, respeitar o que o desvalido tenha a nos dizer. Cunha, no uso dos arquivos amarelados pelo tempo, desvia, embaralha o triunfalismo retilíneo de uma ordem sempre vencedora; diferencia-se do pesquisador comovido pelo excluído como se a ele só restasse a fragilidade desencadeada pela sua dor. Os indícios encontrados na pesquisa, ao contrário dos laudos, desvencilham-se da função de serem pistas reveladoras da conclusão de uma trama. Não são insignificâncias que nos levarão a montagem de uma resposta, de um veredito, como nos romances policiais. A carta é usada como instrumento cortante produtor de cesuras em uma história valente que segue reta a procura do fim. A exasperação das palavras retira da missivista o conforto do reconhecimento de uma identidade, de um tempo classificável ou do lugar específico. $O$ texto de Florinda interrompe o pensamento apressado em direção ao futuro aprisionado no mundo dos heróis e das vítimas; apresenta-nos o incansável exercício das artes do fazer, artes sem a precisão da forma correta ou do ato previsível para se atingir o alvo. O texto desta mulher sugere-nos que alguma coisa ficou na metade do percurso à espera de parceria para continuarmos contando a sua história, sem a comodidade de qualquer pronome no singular ou no plural. A fúria do texto aniquila a mulher negra, louca, semi-analfabeta e não deixa espaço para ninguém confessar eu sou, mas permite que algo impessoal afirme a intensidade de uma história cortante.

Ressaltar a carta como recusa de ser um indício de uma hipótese a ser validada remete à "terna empiria" ${ }^{5}$ de Walter Benjamin, na qual a força da singularidade do fato observado não seria amansada ou neutralizada na inclusão em um sistema de idéias, mas denota ao empírico o sentido de desacomodação, de algo que estanca a agilidade de uma análise na busca da verdade conclusiva. Inspirada em Goethe, esta empiria torna-se terna por recusar ao sujeito a missão onipotente de centralizar em si o desvendamento daquilo que observa, ou a 
impotência da derrota desta missão. O empírico seria terno por seduzir o observador a estar atento ao que escapa a sua sombra, ao fora de si; uma doação que faz da abertura do pensamento o efeito de um contágio, de uma sedução realizada por algo que extrapola o isolamento arrogante da razão ou do sujeito. Solicita ao pesquisador ser vulnerável, adotando uma estratégica fragilidade para disponibilizar-se ao que sucede, ao que possa acontecer. Esta solicitação não é restrita a questões metodológicas. A política da "terna empiria" indica-nos uma proposta ética.

Para a cidade das luzes, o sofrimento de Florinda ou as suas tramas irremediavelmente acabaram com o fechamento do Juquery. A paciente reduz-se à negra, louca e semi-analfabeta. No texto traduzido pelo manicômio, é bloqueado um vazio inominável onde corpos alheios possam ocupá-lo temporariamente. O passado está morto. A história é só dela. Por que a foto era necessária no manicômio? De onde viria este desejo de identificação? O que aconteceu a Regina? Quem foi o culpado? Florinda e Antônia possuíam a imagem do hospício retratada em suas fotos anexadas aos prontuários; eram assim obrigadas por não serem pensionistas pagantes de distintas famílias. Nos prontuários dos negros, pardos, miseráveis, a fotografia funcionava como mais um instrumento para a avaliação diagnóstica. Ali, estampados na pose médica, eram arrancados da noite e falavam sobre os seus destinos. A hierarquia do lado de fora do manicômio atravessava os muros e misturava-se aos desígnios da morbidez mental. A máquina de fazer imagens, inventada do outro lado do Atlântico, chegou a São Paulo para registrar a aura do espírito das personalidades citadinas, o brilho dos coletivos de trabalhadores representando a virtude do trabalho e os indícios mórbidos daqueles com os quais a higiene urbana deveria preocupar-se. Psiquiatria e polícia ganharam deste invento a possibilidade de contar histórias, criar personagens, fazer da imagem a ferramenta precisa para desvendar e provar delitos contra a lei ou para prevenir os perigos misteriosos da natureza humana. A cicatriz marcada a ferro quente no corpo do criminoso do passado torna-se ineficaz na urbe dos oitocentos. A invenção da fotografia amplia a vigilância sobre o delito na esteira das mudanças do movimento, da circulação e do corpo citadino na cidade da luz. O incógnito, misturado ao ritmo frenético das multidões urbanas, onde os rastros apagam-se rapidamente, precisa de cuidados. Segundo Gunning (2004, p. 38-39)

Na criminologia, a fotografia trabalhou em duas direções. Uma delimitou a sua capacidade de capturar a evidência de um crime, o próprio ato desviante A outra prática (menos direta, mas comum) utilizou-a para marcar e não perder de vista o 
criminoso, funcionando como elemento essencial em novos sistemas de identificação. Encontraremos essas duas direções não somente na criminologia, mas também no processo de construção do mito da ficção policial.

A sensação intensa que se dissipa em segundos, desprovida da certeza de a sentirmos novamente, o perder de vista aquilo que se acreditava eterno para nunca mais, imagens que se esvaem, imagens que surgem sem a continuidade da cena, lugares e objetos onde marcas de pertencimento propiciavam segurança, agora acabam no ritmo incontrolável. O momentâneo, a fragmentação de um mundo estável onde se podia prever, antecipar uma ação, oferecem ao homem da modernidade dos oitocentos tormento e esperança. Multidões que ameaçam a ordem das ruas, coletivos ruidosos e informes, atemorizam - citadino devido à perda da estabilidade de si e da conquistada identidade. Locomotivas, iluminação, equipamentos fabris, novos desenhos e funções de objetos impelem-no a circular, produzir, consumir, sugerindo a inesgotabilidade da criatividade humana no lastro da promessa de felicidade anunciada pelo progresso. Nas fábricas, a matéria-prima, em ritmo acelerado, transforma-se em outra coisa; nas ruas, a qualquer momento, acontece algo imprevisível; no citadino, para o seu tormento, o contorno nítido do seu rosto e da sua alma poderá esvaecer como as imagens do lado de fora do seu habitat. Choques urbanos, provocados pela perda do universo onde os astros e os deuses protegiam suas angústias e esperanças, dilaceram totalidades do que seja a vida ou do que seja o sujeito. A fragmentação do tempo, do espaço, do corpo na exigência de formas singulares de experiência, atormentou o citadino da cidade luz. Na tentativa de neutralizar estes choques, o burguês fará do espaço privado o seu universo. Para Benjamin (2006, p.59-60):

O interior não é apenas o universo do homem privado, é também seu estojo. Desde Luís Filipe, encontra-se no burguês esta tendência de indenizar-se da asência de rastros da vida privada na grande cidade. Essa compensação, ele tenta encontrá-la entre as quatro paredes de seu apartamento. Tudo se passa como se fosse uma questão de honra não deixar se perderem os rastros de seus objetos de uso [...] Tem uma clara preferência pelo veludo e a pelúcia que conservam a marca de todo contato. [...] Os vestígios de seu habitante moldam-se no “ intérieur ". Daí nasce o romance policial que pesquisa esses vestígios e segue essas pistas [...] romances policiais de Edgar Poe fazem dele o primeiro fisignomonista do interior Os criminosos nas primeiras narrativas policiais, não são nem marginais, e sim pessoas privadas pertencentes à burguesia. 
No universo repleto de rastros de si, o burguês retém o que o mundo do lado de fora poderá exterminar. Porta-retratos, fotografias nos álbuns da família, objetos pessoais revelam a aura da personalidade do morador. A marca das mãos no veludo prenuncia a integridade de um corpo ainda não aniquilado pelo perigo das multidões; ratifica a solidez da identidade que não se deixa abalar pelo tempo cortante das ruas. Do lado de fora, o caos do acontecimento inesperado, a fugacidade da experiência, o perigo do anonimato. No estojo domiciliar, onde ele habita, a nitidez do espírito e do nome são hermeticamente protegidas das impurezas urbanas. Tudo neste lar representa, evoca a presença e a ausência do proprietário. As imagens dos diferentes momentos da família, registrados nas fotografias, indicam a continuidade harmoniosa do tempo, a aura das individualidades que não se deixa apagar no transcorrer dos anos. O tempo, ali, é contínuo e o espaço, o universo autônomo onde o lado de fora seria um provável adversário. Mesmo sem ninguém habitando este universo, a atmosfera gerada pelo acúmulo de indícios sugere que algo ocupou ou ocupa este lugar. Símbolos, sinais, pistas demandam hermeneutas a procura de mistérios e revelações; território fértil para a missão dos detetives, os da ficção policial ou os criados pelas ciências da alma. Na morada dos rastros, as histórias possuem um início, um meio e um fim, protegidas pelas portas e janelas hermeticamente fechadas, local propício para o desvendamento da alma ou de um crime. O que se sucedeu com Regina? Quem é o culpado? Será o tio? Seria o laudo um texto científico ou uma ficção policial?

Neste universo repleto de significados, de fragmentos que compõem a totalidade de uma história, nada deverá se dispersar. Segundo Oliveira (2006, p. 127), na ficção policial, é destinada ao detetive a seguinte missão:

O detetive enquanto guia de uma narrativa é a síntese de um tipo de homem para qual mundo e sentido só se encontram quando seus elementos dispersos se tornam promessa de totalidade, quando cada objeto isolado se interconecta a todos os outros, tal como num desenho em perspectiva, em que todas as linhas convergem para o mesmo ponto de fuga. Seu segredo, a substância que vicia o leitor , é a tensa promessa deste ponto de fuga , o pressentimento certo de um fim, no qual alguém, de preferência, é culpabilizado pelo desconcerto do mundo, e é então retirado de circulação, a fim de que as peças do mundo se reencaixem. 
Fotografias e literatura nos oferecem modos de contar histórias e estórias, de construção de tempo e de espaço, propondo-nos o sentido particular do que seja a ética da luz. Edgar Allan Poe, o criador do romance policial, assim como o personagem Sherlock Holmes de Conan Doyle, ironizaram esta ética através da literatura. Os cientistas da alma, ao contrário dos detetives, prosseguem na criação do suspense e nas artimanhas para resolvê-lo. O laudo de Regina, escrito na atualidade, e o de Antonia, no início do século XX, alertam para o inacabamento do passado produzido por urgências do agora; urgências passíveis de destruir fronteiras entre ficção e verdade, objetividade científica e subjetivismo da arte, silêncio e poder. Essas vidas infames, arrancadas da noite, são respeitosamente apresentadas ao público em nítidas e conclusivas narrativas.

\section{Noturnos Urbanos}

A noite amedrontou na antigüidade porque, nela, a lua irradiava o seu poder. Segundo Delumeau (2009), o astro noturno enchia o ar de umidade e causava doenças; produzia a loucura. Nesta época, a lua possuía uma ambivalência, acalmava e agitava os mares, fertilizava e destruía plantações. Nos textos bíblicos, a noite ganha o perigo das trevas: "Quando terminar o dia, então sobrevêm os animais maléficos" (SALMOS, 104, 20 apud DELUMEAU, 2009, p. 139) ou "os homens que odeiam a luz - adúlteros, ladrões ou assassinos" (JÓ, 24-13 apud DELUMEAU, 2009, p. 139). Nas cidades laicas, a ordem pública exigirá a iluminação porque a "a noite é suspeita, pactua com os debochados, os ladrões e os assassinos" (DELEMEAU, 2009, p. 149). Foi também o cenário para que os letreiros luminosos desenhassem os contornos da metrópole. A noite abrigou paixões inconfessáveis e mistérios.

Estes significados da noite diferem-se do mencionado por Foucault na introdução deste artigo. A história indica-nos noites particulares, individualizadas por atrações e temores inventados pelas práticas dos homens. A noite da qual os infames são arrancados pelo clarão do poder ainda não é, vive informe, pulsa no inominável, se intensifica como a outra noite. Para Blanchot (1987, p. 169):

A outra noite é sempre o outro, e aquele que o ouve torna-se outro, aquele que se aproxima distancia-se de si, não é mais aquele que se acerca, mas o que se distancia, que vai daqui, de lá. Aquele que entrado na primeira noite, intrepidamente busca caminhar para a sua intimidade mais profunda, para o essencial, num dado momento ouve a outra noite, ouve-se a si mesmo, ouve o eco eternamente repercutido de sua própria caminhada, caminhada na direção do silêncio, mas o eco é-lhe devolvido 
como a imensidade sussurrante, rumo ao vazio, e o vazio é agora uma presença que vem ao seu encontro.

Qual a política deste vazio? Que importância ele teria para as problematizações de uma ética da pesquisa?

A presença do vazio da segunda noite poderá ser encontrada também nas fotografias de Eugène Atget, fotógrafo cuja obra Benjamin (1996, p. 101-102) caracteriza como repleta de imagens do vazio.

\begin{abstract}
Quase sempre Atget passou ao largo das grandes vistas e dos lugares característicos, mas não negligenciou uma grande fila de fôrma de sapateiro, nem os pátios de Paris, onde da manhã à noite se enfileiram carrinhos de mão, nem as mesas com os pratos sujos ainda não retirados [...]. Mas curiosamente quase todas essas imagens são vazias. Vazia a Porte d'Arcueil nas fortificações, vazias as escadas faustosas, vazios os pátios, vazios os terraços dos cafés [...]. Esses lugares não são solitários e sim privados de toda atmosfera; nessa imagens, a cidade foi esvaziada, como uma casa que ainda não encontrou moradores.
\end{abstract}

Para Benjamin (1996, p. 100), Atget foi "o primeiro a desinfetar a atmosfera sufocante difundida pela fotografia convencional". A falta de oxigênio nas cidades projetadas para enaltecer o seu caráter encarnado nos monumentos ou nos traçados das ruas, assim como nas moradias burguesas carregadas de aura, ganham o sopro de ar nas imagens do fotógrafo francês. Atget "desinfeta" o peso do eu, do ele ou do nós de qualquer proprietário de um território e, desta forma, impede o visitante de sentir-se um intruso. Moradias e cidades são atravessadas pelo vazio que seduz quem as olhe a entrar. Ali não encontrará o tempo contínuo ou o espaço familiar, mas a força do acontecimento desencadeado pelo afeto do inominável, que lhe confere o ar necessário para prosseguir na errância. Na moradia ou na cidade vazia, os detalhes não são indícios para se completar uma história ou para se definir uma identidade retratada, mas, sim, o convite para o despedaçamento da solidez do conforto de prováveis conclusões. A Paris, através da arte de Atget, apresenta-nos coisas insignificantes do cotidiano, que desdobram a paisagem e o espectador. São imagens de acontecimentos. À semelhança da segunda noite de Blanchot, aquele que se aproxima dessas imagens não ouvirá o eco de vozes reconhecíveis, mas uma imensidão sussurrante que escapa do pertencimento a um corpo, a uma pátria, a uma voz ou a um silêncio em particular. O vazio presente nas fotografias de Atget sugere-nos que nenhuma dor ou alegria, utopia ou barbárie terão um final que as encarcere. 
Na tradição moçambicana, Guambe e Dzvane são o primeiro homem e a primeira mulher, e deixaram para o mundo um baú repleto de histórias. Os contadores de histórias, quando terminam as suas narrativas, buscando o retorno das mesmas ao lugar de onde saíram, dizem o seguinte: Voltem para a caixa de Guambe e Dzavane. Segundo Mia Couto (2009, p.72) "O que acontece quando não se fecha a história? A multidão que assiste fica doente, contaminada por uma enfermidade que se chama a doença do sonhar."

A caixa aberta deixará que as narrativas escapem, e desta forma elas não terão pouso fixo, um único sujeito, uma história concluída. Nenhuma dor ou forma de extinguí-la terá um proprietário exclusivo. A caixa aberta ficará vazia, as narrativas, inacabadas. Disparadas pelo vazio, terão a forma provisória de como forem contadas. Não exigirão respeito, nem cuidados, porque não estão dentro de nenhum corpo ou alma. Do inominável, nenhuma indiferença se fará presente. Continuaremos doentes; não do sonhar, mas de literatura ou de noite.

\section{Referências Bibliográficas}

BAPTISTA, L. A. O veludo, o vidro e o plástico. Desigualdade e diversidade na metrópole. Niterói: EDUFF, 2009.

BENJAMIN, W. Magia e técnica, arte e política: ensaio sobre literatura e história da cultura. São Paulo: Brasiliense, 1996.

Passagens. Belo Horizonte: Editora UFMG, 2006.

BLÂ̄ COUTO, M. Encontros e Encantos: Rosa em Moçambique. In: STARLING, H. M. M.; ALMEIDA, S. R. G. (Orgs.). Sentimentos do Mundo: Ciclo de Conferências dos anos 80 da UFMG. Belo Horizonte: Editora UFMG, 2009, p. 63-72.

CUNHA, M. C. O espelho do mundo. Juquery, a história de um asilo. Rio de J aneiro: Editora Paz e Terra, 1986.

DELUMEAU, J. História do medo no ocidente. 1300-1800: uma cidade sitiada. São Paulo: Companhia das Letras, 2009.

FOUCAULT, M. A vida dos homens infames. In: FOUCAULT, M. O que é um autor?. Lisboa: Vega, 1992, p. 89-128.

GAGNEBIN. J. M. Posfácio. Uma topografia espiritual. In: ARAGON. L. 0 camponês de Paris. Rio de J aneiro. Imago, 1996, p. 241-259.

GUNNING, T. O retrato do corpo humano: a fotografia, os detetives e os primórdios do cinema. In: CHARNEY, L.; SCHWARTZ, R. (Orgs.). 0 cinema e a invenção da vida moderna. São Paulo: Cosac \& Naify, 2004, p. 33-66. 


\section{OLIVEIRA, B. B. C. Olhar e narrativa: leituras benjaminianas.}

Vitória: Editora EDUFES, 2006.

\section{Endereço para correspondência}

Luis Antonio dos Santos Baptista

UFF, Departamento de Psicologia, Campus do Gragoatá, Bloco O, São Domingos, CEP 24220-008, Niterói - RJ, Brasil

Endereço eletrônico: baptista509@gmail.com

Recebido em: 05/08/2009

Aceito para publicação em: 13/10/2009

Acompanhamento do processo editorial: Deise Mancebo, Marisa Lopes da Rocha e Roberta Romagnoli.

\section{Notas}

1 Este artigo foi inspirado nas discussões metodológicas da pesquisa Histórias Anônimas do Cotidiano Carioca: narrativas de moradores que vivem só.

2 O referido texto é uma criação do autor inspirado em um laudo de uma Vara da Infância e Juventude do Brasil. Os nomes e os locais originais formas modificados.

3 Sobre o perder-se na cidade, ver as análises de Gagnebin (1986, p. 241-259).

${ }^{4}$ Sobre as cartas, ver Baptista (2009, p. 88-91).

${ }^{5}$ Sobre a "terna empiria", ver Benjamin (1996, p. 103).b 